\title{
PERANCANGAN MEDIA PROMOSI DIGITAL MUSEUM TEMBAKAU JEMBER
}

\author{
Alam Budiansya, Yayah Rukiah \\ Program Studi Desain Komunikasi Visual \\ Fakultas Bahasa dan Seni Universitas Indraprasta PGRI \\ Jl. Nangka No.58c, Tanjung Barat, Jakarta Selatan, 12530 \\ alambudiansya@gmail.com
}

\begin{abstract}
Abstrak
Tujuan perancangan media promosi digital ini merupakan sebagai suatu upaya pengenalan Museum Tembakau Jember kepada masyarakat luas terutama masyarakat Jember, melalui media promosi digital atau online dimana saaat ini sebagian masyarakat Indonesia sudah tidak canggung lagi terhadap teknologi sehingga hal tersebut menjadi peluang besar untuk dapat menyebarkan atau mempromosikan suatu tempat dengan cepat dan luas. Penelitian ini menggunakan metode penelitian kualitatif dengan studi literature, observasi dan wawancara langsung dengan pengelola museum. Dalam perancangan ini peneliti merancang media promosi digital berupa e-banner dan web banner yang menggunakan gaya grafis khas dari Museum Tembakau itu sendiri, gaya grafis khas ditentukan oleh peneliti melalui analisa logo Museum Tembakau hingga peneliti dapat menentukan gaya grafis khas yang sesuai dengan Museum Tembakau yang kemudian diterapkan dalam pembuatan media promosi digital tersebut.
\end{abstract}

Kata Kunci: museum tembakau, jember, media promosi, digital

\begin{abstract}
The purpose of this digital promotional media design is as an effort to introduce the Jember Tobacco Museum to the wider community, especially the Jember community, through digital or online promotion media where at present some Indonesian people are no longer awkward about technology so that it becomes a great opportunity to be able to disseminate or promote somewhere quickly and broadly. This study uses qualitative research methods with literature studies, observations and direct interviews with museum managers. In this design researchers design digital promotional media in the form of e-banners and web banners that use the typical graphic style of the Tobacco Museum itself, the typical graphic style is determined by researchers through the Tobacco Museum logo analysis so that researchers can determine the typical graphic style that matches the Tobacco Museum then applied in the manufacture of digital promotional media
\end{abstract}

Keywords: Tobacco Museum, Jember, Media Promotion, Digital

\section{PENDAHULUAN}

Jember yang merupakan salah satu kota besar di Provinsi Jawa Timur memiliki banyak sekali kebudayaan. Salah satu warisan kebudayaan yang ada di Kota Jember yaitu Tembakau, Tembakau memiliki sejarah yang cukup panjang di Kabupaten Jember, hingga Tembakau menjadi sebuah ciri khas bagi Kota Jember itu sendiri. Ciri khas tersebut juga dapat dilihat pada lambang Kota Jember yang terdapat gambar daun Tembakau, hal itu dapat membuktikan bahwa tanaman Tembakau merupakan salah satu hal yang penting bagi Kota Jember (Bella et al., 2017). 
Berbicara Kota Jember memang tidak bisa luput dari Tanaman Tembakau, karena Tanaman Tembakau sudah menjadi suatu warisan kebudayaan dan satu kesatuan terhadap Kota Jember sehingga tidak dapat dipisahkan satu sama lain. Berdasarkan hal tersebut Unit Pelaksana Teknis (UPT) Pengujian Sertifikasi Mutu Barang (PSMB) - Lembaga Tembakau Jember Dinas Perindustrian dan Perdagangan Provinsi Jawa Timur mendirikan sebuah Museum Tembakau yang berada dipusat Kota Jember tepatnya di Kalimantan Nomor 1, Kecamatan Sumbersari Kabupaten Jember Provinsi Jawa Timur. Museum tersebut berada tepat dibelakang kantor Lembaga Tembakau Jember

Berdasarkan hasil observasi yang dilakukan oleh penulis saat mengunjungi Museum Tembakau Jember, Museum tersebut berada di daerah yang cukup ramai karena berada dijalan utama serta banyak dilalui oleh masyarakat, adanya kampus Universitas Jember yang berada didekat museum juga menjadi salah satu alasan museum tersebut berada di daerah yang cukup ramai dilalui masyarakat. Namun ramainya daerah tersebut tidak membuat banyak masyarakat yang tahu akan keberadaan museum tersebut, terutama warga Kota Jember itu sendiri. Dapat dibuktikan dari hasil catatan buku tamu pengelola museum, pengunjung yang datang lebih banyak masyarakat dari luar Kota Jember dibandingkan warga Kota Jember. Selain itu pihak pengelola museum juga kurang aktif dalam mempromosikan Museum Tembakau, terutama secara digital atau online, hal tersebut dapat dilihat dari website Lembaga Tembakau Jember yang sudah kadaluarsa dan sosial media Instagram Museum Tembakau Jember yang sudah tidak aktif lagi. Padahal saat ini sebagian besar masyarakat Indonesia dari usia muda maupun tua sudah tidak canggung lagi dalam menggunakan internet, berdasarkan data Asosiasi Penyelenggara Jasa Internet Indonesia (APJII) dalam Kompas.com (2 Februari 2018) dikatakan bahwa lebih dari 50 persen masyarakat Indonesia atau sekitar 143 juta orang telah terhubung jaringan internet sepanjang 2017, hal itu dapat menjadi peluang yang sangat besar bagi Museum Tembakau Jember untuk mempromosikan dan memperkenalkan Museum Tembakau kepada masyarakat Indonesia secara digital atau online. Berdasarkan hal tersebut sesuai bidang keilmuan penulis dalam kompetensi Desain Komunikasi Visual yaitu suatu disiplin ilmu yang mempelajari konsep-konsep komunikasi serta ungkapan kreatif melalui berbagai media untuk menyampaikan pesan dan gagasan secara visual dengan mengelola elemen-elemen grafis yang berbentuk gambar, tatanan huruf, dan layout. (Kusrianto, 2007: 2) dalam (Subianto, Anto, \& Akbar, 2018). Penulis akan mencoba membantu Museum Tembakau dalam membuat media promosi digital yang difungsikan untuk mempromosikan Museum Tembakau Jember secara online atau melalui internet. Harapannya dengan membuat media promosi digital ini, dapat membuat masyarakat mengetahui keberadaan museum ini, serta mengenal Museum Tembakau. selain itu dapat menjadi daya tarik agar masyarakat dan wisatawan memiliki keinginan untuk datang ke Museum Tembakau.

\section{METODE PENELITIAN}

Dalam penelitian ini, penulis menggunakan metode penelitian kualitatif, dengan teknik pengumpulan data sebagai berikut:

\section{Studi Literatur,}

Penulis mengumpulkan data yang berkaitan dengan penelitian ini melalui buku, artikel jurnal, dan artikel website.

2. Observasi

Penulis mendatangi langsung Museum Tembakau Jember untuk memperoleh data dan mengetahui situasi dan kondisi Museum Tembakau.

3. Wawancara

Wawancara dilakukan dengan pengelola Museum Tembakau yaitu Bapak Sunito yang berperan penting dalam perkembangan museum, tujuannya agar memperoleh data tentang sejarah museum, dan perkembangan museum hingga saat ini. 


\section{HASIL DAN PEMBAHASAN}

\section{Landasan Teori}

Sebelum masuk ke tahap perancangan diperlukan landasan teori untuk memperkuat hasil rancangan yang akan dibuat.

\section{Desain Komunikasi Visual}

Desain Komunikasi Visual yaitu suatu disiplin ilmu yang mempelajari konsep-konsep komunikasi serta ungkapan kreatif melalui berbagai media untuk menyampaikan pesan dan gagasan secara visual dengan mengelola elemen-elemen grafis yang berbentuk gambar, tatanan huruf, dan layout. (Kusrianto, 2007: 2) dalam (Subianto et al., 2018).

\section{Promosi}

Promosi adalah suatu kegiatan bauran pemasaran yang merupakan tahapan penting bagi keberhasilan sebuah produk atau jasa atau bisnis tertentu. Tujuan promosi yaitu untuk membuat konsumen mengetahui produk atau jasa yang ditawarkan (Wijayanti, 2012)

\section{Digital Marketing}

Digital Marketing atau yang lebih dikenal dengan e-marketing, merupakan bentuk usaha dari produsen untuk memasarkan produk dan jasanya serta membangun hubungan dengan pelanggan melalui media internet. Bentuk pemasaran ini pada dasarnya merupakan bagian dari pemasaran langsung (Kotler, 2008) dalam (Tresnawati, 2018).

\section{Tinjauan Objek}

Seperti yang sudah disebutkan sebelumnya, Museum Tembakau Jember yang memiliki lokasi dipusat kota dan berada di tempat yang cukup ramai dilalui oleh masyarakat, sampai saat ini masih banyak sekali masyarakat yang belum mengetahui keberadaan atau pun mengetahui museum ini. walaupun terpampang jelas tulisan Museum Tembakau di depan area jalan sekitar museum, tetapi masih banyak masyarakat yang tidak sadar akan kehadiran museum ini. Kurangnya promosi yang dilakukan oleh pengelola museum merupakan salah satu penyebabnya. Salah satu cara yang tepat untuk mengenalkan museum ini terhadap masyarakat luas di era digital seperti sekarang, yaitu dengan membuat media promosi digital.

\section{Proses Perancangan}

Media promosi digital yang akan dibuat yaitu berupa e-banner dan web banner. dengan ukuran e-banner 1080px x 1080px dan web banner dengan tiga ukuran yang berbeda yaitu 250px x 250px, 240px x 400px, dan 160px x 600px. Untuk penempatan e-banner yaitu pada media sosial Instagram, sedangkan web banner akan ditempatkan pada media-media atau portal berita online. Didalam media promosi digital ini, akan terdapat elemen-elemen desain berupa gambar, tatanan huruf, warna dan layout. Sebelum masuk ketahap perancangan, penulis akan menentukan terlebih dahulu gaya grafis khas yang akan digunakan dalam pembuatan media promosi digital Museum Tembakau Jember. Menurut (Listya, 2016) gaya grafis khas merupakan elemen penting dalam memperkuat identitas visual suatu perusahaan, karena gaya grafis khas akan hampir selalu digunakan pada seluruh media, baik media promosi maupun media lainnya. Dalam penelitian ini penulis akan mencoba membuat media promosi digital sesuai dengan gaya grafis khas Museum Tembakau Jember. Penulis akan mencoba menetukan gaya grafis khas Museum Tembakau Jember dengan mengacu pada logo Museum Tembakau Jember. Desain logo dapat menentukan bagaimana identitas visual yang lainnya dibuat, seperti misalnya warna, huruf, dan juga gaya grafis (Listya, 2016). 


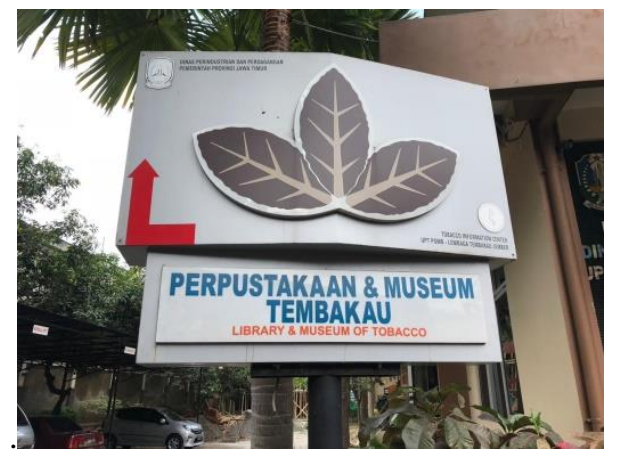

Gambar 1 Logo Museum Tembakau

Sumber: https://www.ceritabangdoel.com/2018/09/sueger-camp-2018-dari-kebun-tembakau.html

Berdasarkan hasil analisa penulis terhadap logo Museum Tembakau Jember, penulis mendapati identitas visual yaitu warna, huruf serta raut bidang pada logo Museum Tembakau.
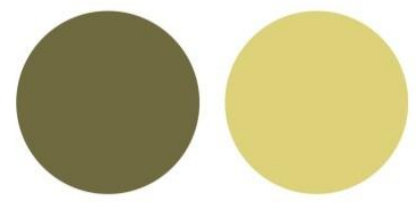

Gambar 2 Warna Identitas Visual Sumber: Dokumen Pribadi

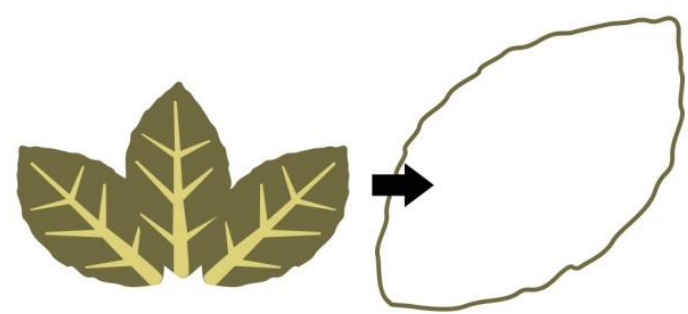

Gambar 3 Raut Bidang pada Logo Museum Tembakau Sumber: Dokumen Pribadi

Dari hasil analisa penulis terhadap logo Museum Tembakau Jember, dapat kita lihat Museum Tembakau memiliki raut bidang yang tidak rapih dan berantakan seperti daun tembakau, serta warna yang digunakan juga warna yang menyerupai daun tembakau. Selain iu font yang digunakan dalam logo Museum Tembakau menggunakan jenis font sans serif. Dari hasil temuantemuan tersebut penulis sudah dapat mengetahui secara garis besar, gaya grafis khas seperti apa yang sesuai dengan Museum Tembakau Jember yang nantinya akan digunakan sebagai media promosi digital maupun media lain untuk kedepannya.

Logo Museum Tembakau terdiri dari tiga daun tembakau yang tersusun secara rapih dan simetris. Untuk menentukan gaya grafis khas, penulis akan menggunakan bagian dari logo. yaitu bagian daun tembakau disisi kanan yang kemudian akan dimiringkan lagi sampai kemiringan 81 derajat.

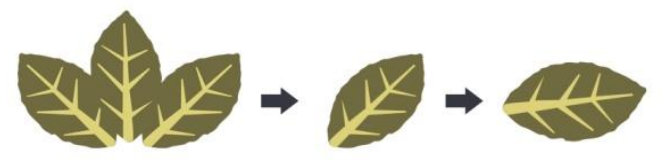

Gambar 4 Bagian Logo Museum Tembakau yang akan digunakan sebagai gaya grafis khas Sumber: Dokumen Pribadi 
Kemudian penulis akan mengambil bagian pada area logo yang sudah dimiringkan tersebut, untuk menentukan warna, penulis menentukan warna dari kombinasi gradasi warna logo Museum Tembakau itu sendiri. Bagian tersebutlah yang akan dijadikan sebagai gaya grafis khas.

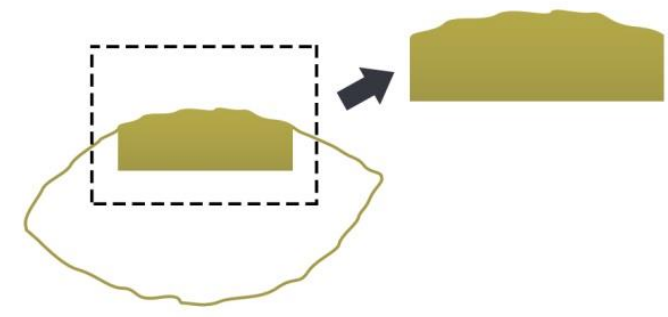

Gambar 5 Menentukan gaya grafis khas dari logo Museum Tembakau Sumber: Dokumen Pribadi

Setelah gaya grafis khas sudah ditentukan, penulis akan memulai perancangan media promosi digital. Dalam perancangan media promosi digital ini, penulis akan menggunakan foto yang secara langsung akan memperlihatkan bagian ruangan dari Museum Tembakau, karena hal tersebut akan menjadi daya tarik tersendiri bagi khalayak, selain itu di dalam media promosi digital tersebut nantinya akan ada penyampaian pesan berupa ajakan untuk mengunjungi Museum Tembakau agar menarik khalayak untuk datang mengunjungi museum tembakau.

Pesan yang nanti digunakan dalam media promosi digital yaitu "Yuk, Mengenal lebih jauh tanaman tembakau!" pesan tersebut dipilih karena di Museum Tembakau para pengunjung dapat melihat sisi lain dari tanaman tembakau, tembakau yang selama ini dikenal oleh masyarakat sebagai bahan dasar cerutu dan rokok saja, ternyata memiliki banyak nilai edukasi. Seperti sejarah tembakau di dunia, di Indonesia, serta di Kota Jember yang merupakan salah satu kota penghasil tembakau terbaik di dunia. Selain itu para pengunjung juga dapat melihat produk lain dari tanaman tembakau yang bermanfaat seperti pestisida, sabun, hingga parfum. Kemudian didalam media promosi digital tersebut nantinya akan menggunakan tagar \#AyoKeMuseum, tujuannya adalah sebagai kampanye untuk mengajak masyarakat mengunjungi museum. Selain itu elemen pendukung lain juga akan dimasukan kedalam media promosi digital, seperti logo Museum Tembakau Jember dan logo Jember Tourism, logo Jember Tourism dimasukan karena Museum Tembakau Jember merupakan bagian dari destinasi wisata edukasi Kabupaten Jember.

Font yang digunakan dalam perancangan media promosi digital ini yaitu Avenir LT Std dengan jenis font sans serif. Font tersebut dipilih karena sesuai dengan identias visual Museum Tembakau Jember yang menggunakan jenis font sans serif.

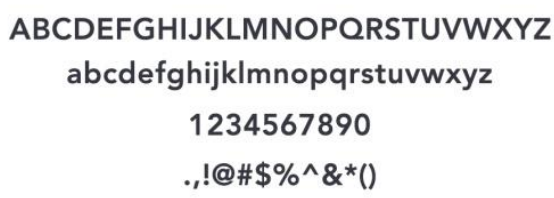

Gambar 6 Font yang digunakan tunk perancangan Sumber: Dokumen Pribadi

Tata letak pada perancangan media promosi digital menyesuaikan dengan ukuran-ukuran media dan gaya grafis yang sudah ditentukan sebelumnya, ukuran yang akan dibuat yaitu 1080px x 1080px, 250px x 250px, 240px x 400px, dan 160px x 600px. 


\section{Hasil Perancangan}

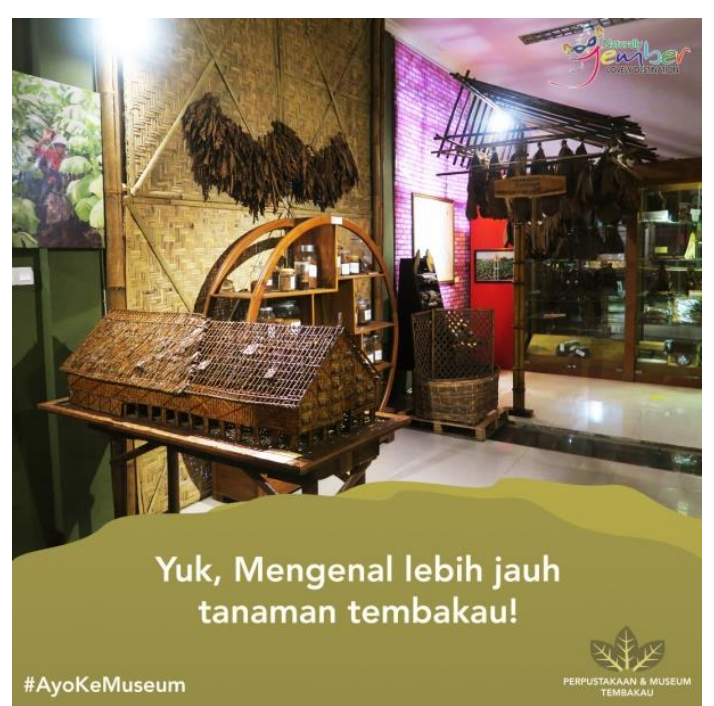

Gambar 7 e-banner ukuran 1080px x 1080px Sumber: Dokumen Pribadi

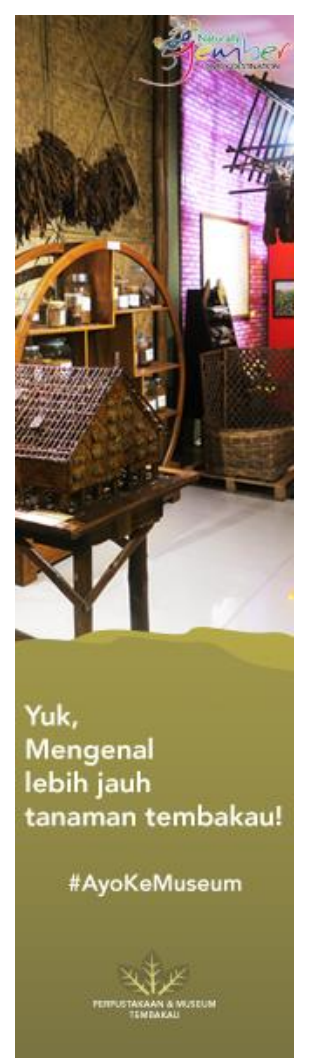

Gambar 8 Web banner ukuran 160px x 600px Sumber: Dokumen Pribadi 


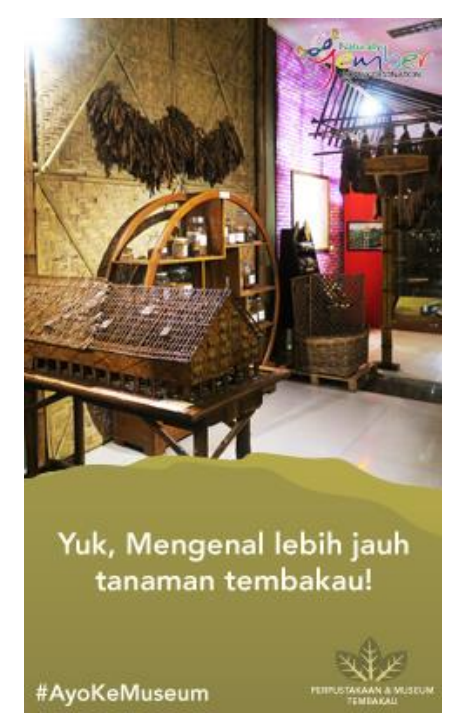

Gambar 9 Web banner ukuran 240px x 400px Sumber: Dokumen Pribadi

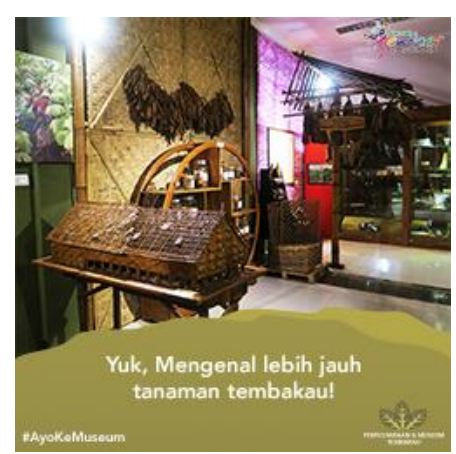

Gambar 10 Web banner 250px x 250px Sumber: Dokumen Pribadi

\section{SIMPULAN}

Berdasarkan hasil penelitian diatas dapat disimpulkan bahwa Museum Tembakau Jember sebagai tempat yang memiliki nilai edukasi tinggi terutama bagi masyarakat jember dan sebagai tempat pelestarian suatu warisan budaya masyarakat jember yaitu tanaman tembakau, sangat perlu diketahui oleh masyarakat luas terutama masyarakat jember itu sendiri, terutama dizaman sekarang ini disaat sebagian masyarakat Indonesia sudah mengenal teknologi, penyebaran informasi sangat begitu cepat dan mudah, untuk itu perlu adanya media promosi secara digital atau online. Terutama untuk mempromosikan suatu tempat yang memiliki banyak nilai edukasi bagi masyarakat, karena hal tersebut merupakan suatu upaya bagi pengenalan budaya suatu tempat agar budaya tersebut tetap terjaga dan dilestarikan secara turun temurun bagi masyarakat itu sendiri.

\section{DAFTAR PUSTAKA}

Wijayanti, T. (2012). Marketing Plan! Perlukah. Jakarta: Elex Media Komputindo.

Bella, K. O. (2017). Peranan perpustakaan dan museum tembakau dalam pelestarian kebudayaan kota jember. BIBLIOTIKA: Jurnal Kajian Perpustakaan dan Informasi, 1(1), 42-57. Retrieved from http://download.portalgaruda.org/article.php?article $=492670 \& v a l=$ 10072\&title=PERANAN PERPUSTAKAAN DAN MUSEUM TEMBAKAU DALAM PELESTARIAN KEBUDAYAAN KOTA JEMBER 
Listya, A. (2016). Bukan sekadar hiasan: Gaya grafis khas sebagai identitas visual korporat. Jurnal Desain, 3(02), 107-117.

Subianto, I. B., Anto, P., \& Akbar, T. (2018). Perancangan poster sebagai media edukasi peserta didik. Jurnal Desain, 5(3), 215-222. Retrieved from http://journal.lppmunindra.ac.id/index.php/Jurnal_Desain/article/view/2425

Tresnawati, Y., \& Prasetyo, K. (2018). Pemetaan konten promosi digital bisnis kuliner kika's catering di media sosial. PRofesi Humas, 3(1), 102-119. 